\title{
Correction to: Improving the Epidemiological Understanding of the Dynamic Relationship Between Life Course Financial Well-being and Health
}

\author{
Samuel L. Swift ${ }^{1,2} \cdot$ Zinzi Bailey $^{3} \cdot$ Adina Zeki Al Hazzouri $^{1}$
}

Published online: 4 April 2019

(C) Springer Nature Switzerland AG 2019

Correction to: Current Epidemiology Reports (2019) 6:28-33 https://doi.org/10.1007/s40471-019-0181-4

The original version of this article unfortunately contained a mistake. The name of the third author should be presented as "First name: Adina" "Last name: Zeki Al Hazzouri" and should be cited as Zeki Al Hazzouri, A.

Publisher's Note Springer Nature remains neutral with regard to jurisdictional claims in published maps and institutional affiliations.

The online version of the original article can be found at https://doi.org/ 10.1007/s40471-019-0181-4

Samuel L. Swift

sls343@med.miami.edu

1 Division of Epidemiology, Department of Public Health Sciences, University of Miami, Miami, FL, USA

2 Division of Epidemiology and Populations Health Sciences, Department of Public Health Sciences, University of Miami Miller School of Medicine, Miami, FL, USA

3 Jay Weiss Institute for Health Equity, Sylvester Comprehensive Cancer Center, University of Miami, Miami, FL, USA 